\title{
Phase Segregation Assisted Morphology Sculpting: Growth of Graphite and Silicon Crystals via Vapor-Solid Reactions
}

\author{
Chih-Hao Huang, ${ }^{\dagger}$ Yu-Hsu Chang, ${ }^{\dagger, \dagger}$ Huang-Kai Lin, ${ }^{\dagger}$ Chih-Wei Peng ${ }^{\dagger, \S}$ Wen-Sheng Chung, ${ }^{\dagger}$ \\ Chi-Young Lee, ${ }^{*}, l$ and Hsin-Tien Chiu*, ${ }^{\dagger}$ \\ Department of Applied Chemistry, National Chiao Tung University, Hsinchu, Taiwan, 30050, ROC, Center for \\ Nanotechnology, Materials Science and Microsystems, National Tsing Hua University, Hsinchu, Taiwan, \\ 30043, ROC, and Institut des Matériaux Jean Rouxel, LPC, 2 Rue de la Houssinière, BP 32229, \\ 44322 Nantes Cedex 3, France
}

Received: October 12, 2006; In Final Form: January 23, 2007

\begin{abstract}
Crystalline graphite and $\mathrm{Si}$ showing fertile morphologies are prepared via vapor-solid reaction growth (VSRG). By reacting $\mathrm{CaC}_{2}$ with vapors of $\mathrm{C}_{x} \mathrm{Cl}_{y}\left(\mathrm{C}_{x} \mathrm{Cl}_{y}\right.$ : $\mathrm{CCl}_{4}, \mathrm{C}_{2} \mathrm{Cl}_{4}, \mathrm{C}_{4} \mathrm{Cl}_{6}$, and $\left.\mathrm{C}_{5} \mathrm{Cl}_{6}\right)$, porous, fibrous, and planar graphite were obtained at 973-1023, 1073-1123, and 1123-1223 K, respectively. Employing $\mathrm{SiCl}_{4}$ to react with $\mathrm{M}_{x} \mathrm{Si}_{y}\left(\mathrm{M}_{x} \mathrm{Si}_{y}: \mathrm{Mg}_{2} \mathrm{Si}\right.$ and $\left.\mathrm{CaSi}_{2}\right)$ generated many Si structures. These include clustered-particle and porous, wirelike, corallike, and planar or platelike at 1023, 1073, 1123, and $1223 \mathrm{~K}$, respectively. The reaction products, the network solids (graphite and $\mathrm{Si}$ ) and the ionic solids $\mathrm{MCl}_{2}$, phase-segregated into self-templating molds and casts and develop cooperatively into various three-dimensional structures. Final morphology of the network solids depends not only on the reaction temperature but their molar volume ratio to the $\mathrm{MCl}_{2} \mathrm{salt}$ products.
\end{abstract}

\section{Introduction}

Varying morphology, including shape and dimensionality, and tuning sizes of nanostructures may provide means to tailor physical and chemical properties of functional materials. Many studies have demonstrated how to achieve the control through various synthetic strategies. ${ }^{1-7}$ These include reactions performed under mild conditions such as chemical precipitation, sol, micelle, and sol-gel processes. In addition, there are processes demanding vigorous conditions, for example, hydrothermal synthesis, pyrolysis, and vapor deposition. ${ }^{8}$ Syntheses of group 14 elements in their network solid forms are also under intensive investigation because of their importance to technological development. Via many specialized routes, carbon and silicon have been synthesized into particle, porous, fibrous, and planar forms. ${ }^{9-20}$ Usually, the reported fabrication methods can only be applied to develop samples with a limited number of dimension and morphology. Previously, we have reported that by employing simple vapor-solid reaction growth (VSRG) methods, many types of materials can be produced at the vaporsolid interface, which is an intrinsically anisotropic growth environment. ${ }^{21-24}$ Products from VSRG are usually phasesegregated and self-templating to offer uniquely shaped products. For example, through VSRG, silicon carbide can be fabricated into cubic shells and cages. ${ }^{24}$

Here, we report that via simple VSRG, highly crystalline graphite and silicon materials can be synthesized at relatively low temperatures $973-1223 \mathrm{~K}$. More interestingly, we discov-

\footnotetext{
* To whom correspondence should be addressed. E-mail: htchiu@ faculty.nctu.edu.tw.

Department of Applied Chemistry, National Chiao Tung University.

$\doteqdot$ Current address: Department of Materials and Mineral Resources Engineering, National Taipei University of Technology, Taipei, Taiwan, 10608, ROC.

$\S$ Institut des Matériaux Jean Rouxel.

"Cneter for Nanotechnology, Materials Science, and Microsystems, National Tsing Hua Unviersity.
}

ered that the morphology of the as-formed structures can be directly manipulated mainly by varying the reaction temperatures. This appears to be an action of phase segregation of the network solid and the ionic salt products. The observation is parallel to minerals formed in the earth's crust. In nature, spherical, porous, fibrous, dendridic, and other shaped crystals appear in multiphase rocks solidified under various conditions. ${ }^{25,26}$ Many eutectic metal alloys also show similar behavior. ${ }^{27}$ In addition, the observed product structural variations are analogous to morphology alterations from phase segregation found in diblock and triblock copolymer systems. ${ }^{28,29}$ In these, due to chemical incompatibility, each one of the component blocks self-assembles into nanophases discretely ordered and arranged. Cooperatively, they generate spherical, cylindrical, and lamellar structures. ${ }^{30,31}$ Our discoveries, including syntheses, characterization, and effects of reaction temperature and molar volume ratio, are discussed below.

\section{Experimental Section}

2.1. Synthesis of Graphite Crystals. $\mathrm{C}_{x} \mathrm{Cl}_{y}$ were purchased either from Aldrich $\left(\mathrm{CCl}_{4}, 99.5 \% ; \mathrm{C}_{2} \mathrm{Cl}_{4}, 99 \% ; \mathrm{C}_{5} \mathrm{Cl}_{6}, 98 \%\right)$ or from ACROS $\left(\mathrm{C}_{4} \mathrm{Cl}_{6}, 98 \%\right)$ [Caution! $\mathrm{LD}_{50}\left(\mathrm{~g} \mathrm{~kg}^{-1}\right)$ oral: for $\mathrm{CCl}_{4}, 3.6$ (mouse); for $\mathrm{C}_{2} \mathrm{Cl}_{4}, 6.4$ (rat); for $\mathrm{C}_{4} \mathrm{Cl}_{6}, 0.09$ (mouse); for $\mathrm{C}_{5} \mathrm{Cl}_{6}, 0.5$ (rat)]. $\mathrm{CaC}_{2}(80 \%)$ was supplied by Aldrich (Caution! $\mathrm{CaC}_{2}$ drastically reacts with water to produce flammable acetylene gas). Different experimental parameters of the reactions between $\mathrm{C}_{x} \mathrm{Cl}_{y}$ and $\mathrm{CaC}_{2}$ are listed in Table 1. A reaction employing $\mathrm{C}_{4} \mathrm{Cl}_{6}$ to react with $\mathrm{CaC}_{2}$ is described below as an example.

In a tubular reactor at $1 \mathrm{~atm}$ and $1223 \mathrm{~K}$, powders of $\mathrm{CaC}_{2}$ $(0.5 \mathrm{~g})$ in an aluminum oxide boat were allowed to react with $\mathrm{C}_{4} \mathrm{Cl}_{6}$ evaporated at $333 \mathrm{~K}$ under bubbling $\mathrm{Ar}\left(30 \mathrm{~cm}^{3}(\mathrm{STP})\right.$ $\min ^{-1}$ ) for $18 \mathrm{~h}$. The as-prepared black products were further 
TABLE 1: Summary of Reaction Conditions and Product Morphology of Graphite Crystals Formed by Reacting CaC $\mathrm{C}_{2}$ and $\mathrm{C}_{x} \mathrm{Cl}_{y}$

\begin{tabular}{|c|c|c|c|c|c|}
\hline $\begin{array}{l}\text { precursor } \\
\mathrm{C}_{x} \mathrm{Cl}_{y}\end{array}$ & vaporization condition $^{a}$ & reacn temp $(\mathrm{K})$ & graphite product morphology ${ }^{b}$ & $\begin{array}{l}\mathrm{La}^{c} \\
(\mathrm{~nm})\end{array}$ & $\begin{aligned} \mathrm{Lc}^{d} \\
(\mathrm{~nm})\end{aligned}$ \\
\hline \multirow[t]{3}{*}{$\mathrm{CCl}_{4}$} & $5 \mathrm{~cm}^{3}(\mathrm{STP}) \mathrm{min}^{-1}$ at $255 \mathrm{~K}, 1 \mathrm{~atm}$ & 1023 & porous: pore size, $400-650 \mathrm{~nm}$; wall thickness, $100-180 \mathrm{~nm}$ & 2.65 & 1.01 \\
\hline & & 1123 & fibrous: diam, $80-110 \mathrm{~nm}$; length, tens of micrometers & 3.47 & 7.15 \\
\hline & & 1223 & planar: thickness, $70-150 \mathrm{~nm}$; plate diam, $1-4 \mu \mathrm{m}$ & 4.57 & 8.42 \\
\hline \multirow[t]{3}{*}{$\mathrm{C}_{2} \mathrm{Cl}_{4}$} & $5 \mathrm{~cm}^{3}(\mathrm{STP}) \mathrm{min}^{-1}$ at $298 \mathrm{~K}, 1 \mathrm{~atm}$ & 973 & porous: pore size, $250 \mathrm{~nm}$ to $1 \mu \mathrm{m}$; wall thickness, $20-70 \mathrm{~nm}$ & 2.43 & 1.03 \\
\hline & & 1073 & fibrous: diam, $25-45 \mathrm{~nm}$; length, tens of micrometers & 2.81 & 2.41 \\
\hline & & 1123 & planar: thickness, $15-75 \mathrm{~nm}$; plate diam, $500 \mathrm{~nm}$ to $3 \mu \mathrm{m}$ & 2.87 & 5.31 \\
\hline \multirow{3}{*}{$\mathrm{C}_{4} \mathrm{Cl}_{6}$} & $30 \mathrm{~cm}^{3}(\mathrm{STP}) \mathrm{min}^{-1}$ at $333 \mathrm{~K}, 1 \mathrm{~atm}$ & 1023 & porous: pore size, $50-400 \mathrm{~nm}$; wall thickness, $15-45 \mathrm{~nm}$ & 2.94 & 1.45 \\
\hline & & 1123 & fibrous: diam, $60-120 \mathrm{~nm}$; length, $1-3 \mu \mathrm{m}$ & 5.57 & 9.61 \\
\hline & & 1223 & planar: thickness, $15-60 \mathrm{~nm}$; plate diam, $400 \mathrm{~nm}$ to $1 \mu \mathrm{m}$ & 9.66 & 9.81 \\
\hline \multirow[t]{3}{*}{$\mathrm{C}_{5} \mathrm{Cl}_{6}$} & $5 \mathrm{~cm}^{3}(\mathrm{STP}) \mathrm{min}^{-1}$ at $281 \mathrm{~K}, 1 \mathrm{~atm}$ & 1023 & $\begin{array}{l}\text { porous: pore size, } 150 \mathrm{~nm} \text { to } 1.5 \mu \mathrm{m} \text {; } \\
\text { wall thickness, } 100-400 \mathrm{~nm}\end{array}$ & 2.81 & 1.35 \\
\hline & & 1123 & fibrous: diam, $35-60 \mathrm{~nm}$; length, $1.5-2 \mu \mathrm{m}$ & 4.18 & 7.74 \\
\hline & & 1223 & planar: thickness, $100-200 \mathrm{~nm}$; plate diam, several micrometers & 7.80 & 9.49 \\
\hline
\end{tabular}

${ }^{a}$ Precursors bubbled under a flow of Ar gas. ${ }^{b}$ Graphite products morphologies observed from SEM and TEM images. ${ }^{c}$ La, showing approximate orderness in graphite hexagonal planes, is directly proportional to the inverse of area ratio between D and G bands in a Raman spectrum of graphite. ${ }^{36}{ }^{d} \mathrm{Lc}$, an estimate of repeating orderness of the graphite layers, which is the thickness of graphite domains, can be calculated using the Scherrer equation. ${ }^{32}$

washed twice in refluxing distilled water $(300 \mathrm{~mL})$ overnight to remove $\mathrm{CaCl}_{2}$. A purified black product $(0.28 \mathrm{~g})$ was obtained.

2.2. Synthesis of Silicon Crystals. $\mathrm{Mg}_{2} \mathrm{Si}(99.5 \%)$ and $\mathrm{CaSi}_{2}$ $(95 \%)$ were purchased from Strem, and $\mathrm{SiCl}_{4}(99 \%)$ was obtained from Aldrich. In general, in a tubular reactor at 1023$1223 \mathrm{~K}$ and $100 \mathrm{kPa}$, a silicide powder in an aluminum oxide boat was reacted with $\mathrm{SiCl}_{4}$ evaporated at $255 \mathrm{~K}$ under bubbling $\operatorname{Ar}\left(5 \mathrm{~cm}^{3}(\mathrm{STP}) \mathrm{min}^{-1}\right)$ for $16 \mathrm{~h}$. The as-prepared products were further heat-treated at $1073 \mathrm{~K}$ and $0.13 \mathrm{~Pa}$ for $1 \mathrm{~h}$ to evaporate the chloride salts $\left(\mathrm{MgCl}_{2}\right.$ and $\left.\mathrm{CaCl}_{2}\right)$. After the workup process, a purified product was collected.

2.3. Characterization. Morphology and structure of the products were evaluated using a scanning electron microscope (SEM, JEOL JSM-6330F, operated at $15 \mathrm{kV}$ ), a transmission electron microscope (TEM, JEOL JEM-4000EX, operated at $400 \mathrm{kV}$ ), an X-ray diffractometer (XRD, Bruker D8 Advance, $\mathrm{K} \alpha$ radiation at $40 \mathrm{kV}$ and $40 \mathrm{~mA}$ ) and a Raman spectrometer (Jabin-Yvon T-64000 with the incident wavelength at $514.5 \mathrm{~nm}$ ). Energy dispersive X-ray spectroscopy (EDX) was used to confirm the element composition of the samples. The results will be discussed in the text below and are shown in the Supporting Information.

2.4. Fractal Dimension Analysis. Projected two-dimensional silhouettes of the samples were processed from selected SEM and TEM data with appropriate magnification using Acrobat Photoshop. The processed images were analyzed by fractal analysis software Fractalyse 2.4, developed by Pierre Frankhauser, Cécile Tannier, and Gilles Vuidel in Laboratoire ThéMA, UMR 6049, Université de Franche-Comté, France. The software can be downloaded from www.fractalyse.org without charge.

\section{Results}

3.1. Preparation and Characterization of Graphite Crystals. Solids of $\mathrm{CaC}_{2}$ were reacted with vapors of $\mathrm{C}_{x} \mathrm{Cl}_{y}\left(\mathrm{CCl}_{4}\right.$, $\mathrm{C}_{2} \mathrm{Cl}_{4}, \mathrm{C}_{5} \mathrm{Cl}_{6}, \mathrm{C}_{4} \mathrm{Cl}_{6}$ ) at elevated temperatures $973-1223 \mathrm{~K}$ to offer black raw products. Table 1 summarizes the reaction parameters and the results of characterization, which will be discussed below.

Morphology Studies of Graphite Crystals by SEM. Images of some typical raw products formed from the reactions between $\mathrm{CaC}_{2}$ and $\mathrm{C}_{x} \mathrm{Cl}_{y}$ are shown in Figure 1. Using $\mathrm{CCl}_{4}$, ball-shaped particles are formed at $1023 \mathrm{~K}$ as the raw product, as shown in Figure 1A. Several ripped particles displayed in the image also suggest that the balls may have a core-shell structure. Energy dispersive X-ray spectrum (Figure 1B) of the product shows the presence of $\mathrm{C}, \mathrm{Ca}$. and $\mathrm{Cl}$. Common chemical knowledge would suggest that the product is a composite of $\mathrm{C}$ and $\mathrm{CaCl}_{2}$. The presence of $\mathrm{CaCl}_{2}$ is confirmed by an XRD study. In addition to reflections from graphite, which will be discussed further below, reflections from $\mathrm{CaCl}_{2}\left(\mathrm{H}_{2} \mathrm{O}\right)_{x}, \mathrm{CaCl}_{2}$ hydrated in moist air, were also observed. Figure $1 \mathrm{C}$ shows the sample obtained from the reaction between $\mathrm{CaC}_{2}$ and $\mathrm{CCl}_{4}$ at $1123 \mathrm{~K}$. The image demonstrates light and dark stripes on the surface. EDX (Figure 1D) also shows that the sample contains $\mathrm{C}, \mathrm{Ca}$, and $\mathrm{Cl}$. At $1223 \mathrm{~K}$, the observed product from the reaction involving $\mathrm{CaC}_{2}$ and $\mathrm{C}_{5} \mathrm{Cl}_{6}$, as shown in Figure $1 \mathrm{E}$, is aggregates of thin plates. Signals from $\mathrm{C}, \mathrm{Ca}$, and $\mathrm{Cl}$ atoms are detected in Figure 1F.

Raw products were washed with distilled water for a long period of time to remove $\mathrm{CaCl}_{2}$. Images of purified examples, prepared from the reactions between $\mathrm{CaC}_{2}$ and $\mathrm{C}_{4} \mathrm{Cl}_{6}$, are shown in Figure 2. The SEM image in Figure 2A suggests that the sample synthesized at $1023 \mathrm{~K}$ contains innumerable pores. A TEM study revealed that the pore size was $50-400 \mathrm{~nm}$, while the thickness was $15-45 \mathrm{~nm}$. Increasing the reaction temperature to $1123 \mathrm{~K}$, a one-dimensional fibrous material (diameter of $60-120 \mathrm{~nm}$ and length of $1-3 \mu \mathrm{m}$ by TEM), shown in Figure $2 \mathrm{~B}$, is isolated. The product formed at $1223 \mathrm{~K}$ shows mainly thin planar structure (thickness of $15-60 \mathrm{~nm}$ and width of $0.4-1$ $\mu \mathrm{m}$ by TEM) in Figure $2 \mathrm{C}$. EDX spectra confirmed that the solid products are composed of carbon. No other signals were observed. Reactions employing various organoperchloro compounds displayed very similar correlation between reaction temperature and product morphology, i.e., the structure changed from porous to fibrous and then to lamellar as the reaction temperature was raised. Also, for all reactions, morphology of the raw products (Figure 1) correlated well with that of the samples free of $\mathrm{CaCl}_{2}$ (Figure 2). This suggests that the products were shaped by segregated salt and carbon phases cooperatively.

Structural Characterization of Graphite Crystals by XRD, Raman, and HRTEM. XRD was employed to structurally characterize the purified products. An example of the product synthesized from $\mathrm{C}_{4} \mathrm{Cl}_{6}$ and $\mathrm{CaC}_{2}$ is described. The patterns showed major reflections with increasing intensity at $2 \theta=25.5$ $(d=0.350 \mathrm{~nm}), 26.0(d=0.342 \mathrm{~nm})$, and $26.2^{\circ}(d=0.340$ $\mathrm{nm})$ for the samples grown at 1023, 1123, and $1223 \mathrm{~K}$, respectively. These $2 \theta$ values are slightly smaller than that of 


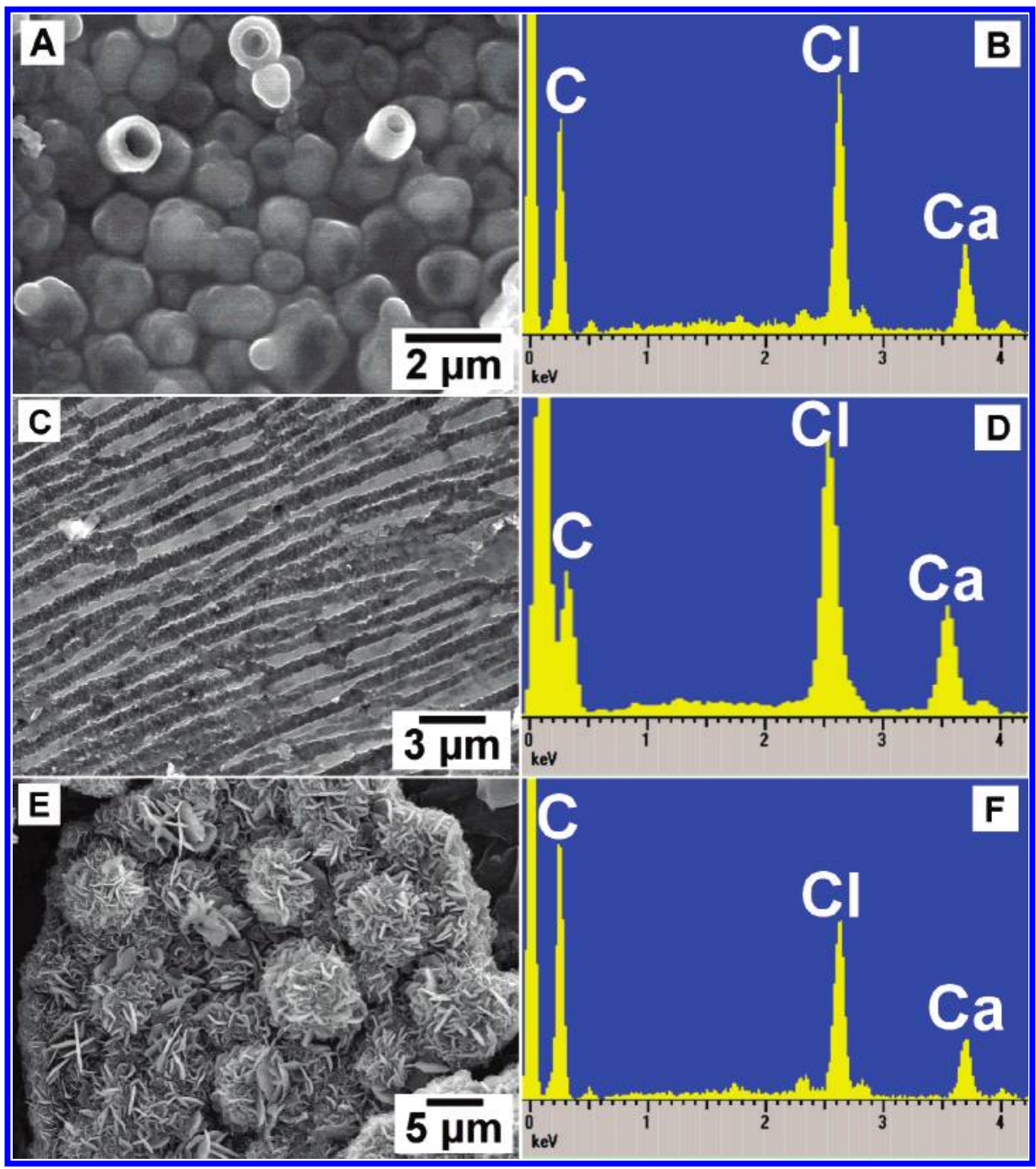

Figure 1. SEM and EDX graphite/CaCl $\mathrm{Cl}_{2}$ nanostructures synthesized from $\mathrm{CaC}_{2}$ and $\mathrm{C}_{x} \mathrm{Cl}_{y}$ : (A) $\mathrm{SEM}$ and (B) EDX of the as-prepared product grown at $1023 \mathrm{~K}_{\text {from }} \mathrm{CCl}_{4}$; (C) SEM and (D) EDX of the as-prepared product grown at $1123 \mathrm{~K}_{\text {from CCl }}$; (E) SEM and (F) EDX of the as-prepared product grown at $1223 \mathrm{~K}$ from $\mathrm{C}_{5} \mathrm{Cl}_{6}$.

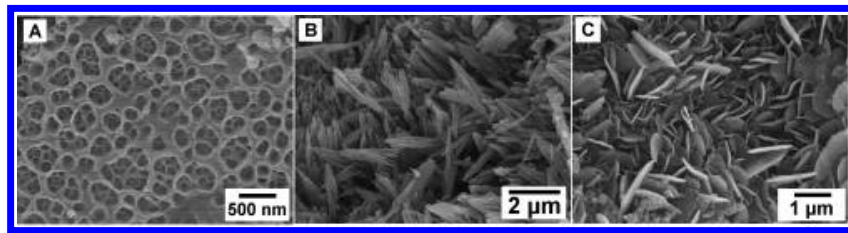

Figure 2. SEM images of graphite products prepared from $\mathrm{CaC}_{2}$ and $\mathrm{C}_{4} \mathrm{Cl}_{6}$ products after the removed of $\mathrm{CaCl}_{2}$ : (A) porous carbon, prepared at $1023 \mathrm{~K}$; (B) fibrous carbon, prepared at $1123 \mathrm{~K}$; (C) planar carbon, prepared at $1223 \mathrm{~K}$.

graphite (JCPDS 23-0064), which is at $2 \theta=26.5^{\circ}(d=0.336$ $\mathrm{nm})$. The value Lc, stacking height of layer planes, can be calculated using the Scherrer equation. Lc is an estimate of repeating orderness of the graphite layers, which is the thickness of graphite domains. ${ }^{32}$ In Figure $3 \mathrm{~A}$, the Lc data are plotted against the reaction temperature. In general, Lc, an index of crystallinity, increases with the increasing temperature. Among the organoperchloro compounds employed, the samples prepared from $\mathrm{C}_{4} \mathrm{Cl}_{6}$ offer the optimum result. The highest $\mathrm{Lc}, 9.81 \mathrm{~nm}$, is observed for a sample grown at $1223 \mathrm{~K}$. This is comparable to Lc of a synthesized graphitic carbon material, which was heat-treated above $2773 \mathrm{~K}, 6-8 \mathrm{~nm} .{ }^{33,34} \mathrm{Also}$, the Lc of natural graphite is around $22 \mathrm{~nm} .{ }^{35}$

Raman spectroscopy is another method frequently used to estimate the crystallinity of carbon materials. A sharp vibration

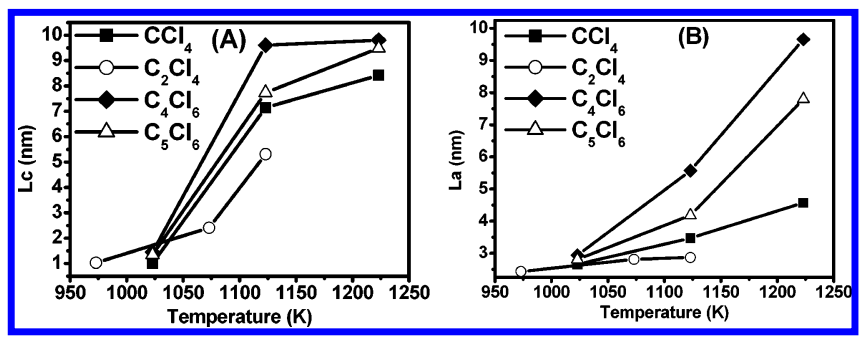

Figure 3. (A) $\mathrm{Lc}$ and (B) $\mathrm{La}$ of the graphite prepared from $\mathrm{CaC}_{2}$ and $\mathrm{C}_{x} \mathrm{Cl}_{y}$ at different temperatures.

mode at $1580 \mathrm{~cm}^{-1}$, called the first-order $\mathrm{G}$ band, is due to $\mathrm{sp}^{2}$-bonded carbon domains in crystalline graphite. The peak at around $1360 \mathrm{~cm}^{-1}$ is regarded as disordered structure and is labeled as the $\mathrm{D}$ band. The value $\mathrm{La}$, which shows approximate orderness in graphite hexagonal planes, is directly proportional to the inverse of area ratio between $\mathrm{D}$ and $\mathrm{G}$ bands, $I_{\mathrm{D}} / I_{\mathrm{G}} \cdot{ }^{36} \mathrm{All}$ spectra of the products grown from $\mathrm{C}_{x} \mathrm{Cl}_{y}$ at $1023-1223 \mathrm{~K}$ displayed $\mathrm{D}$ and $\mathrm{G}$ bands at 1580 and $1360 \mathrm{~cm}^{-1}$, respectively. In this study, the $\mathrm{D}$ band signal intensity decreased with increasing reaction temperature, indicating that $I_{\mathrm{D}} / I_{\mathrm{G}}$ increases very significantly. Consequently, as shown in Figure $3 \mathrm{~B}$, the La value increases with increasing reaction temperature. This suggests that the graphite domain size expands and forms a highly oriented structure at high reaction temperatures. The 


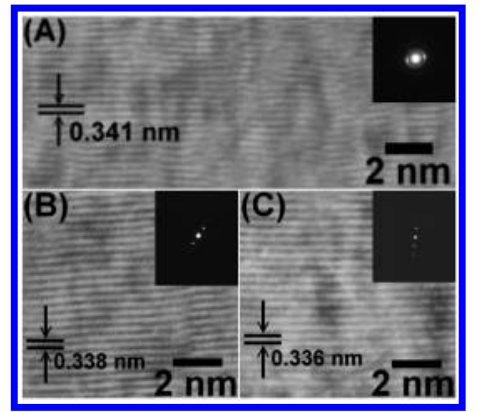

Figure 4. HRTEM and SAED (inset) images of graphite grown from $\mathrm{CaC}_{2}$ and $\mathrm{C}_{4} \mathrm{Cl}_{6}$ at (A) 1023, (B) 1123 , and (C) $1223 \mathrm{~K}$

graphite product synthesized from $\mathrm{C}_{4} \mathrm{Cl}_{6}$ also shows the optimum La, $9.66 \mathrm{~nm}$, among the ones grown from other organoperchloro compounds employed. In other reports, graphite synthesized at high temperatures showed comparative La values of less than $10 \mathrm{~nm} \cdot{ }^{37-39}$ On the other hand, La of commercial graphite, which was processed at high temperature for a long period of time, is $31.7 \mathrm{~nm} .{ }^{40}$ The detailed values of $\mathrm{Lc}$ and $\mathrm{La}$ are listed in Table 1. Both Lc and La values suggest that more ordered graphites are produced using $\mathrm{C}_{4} \mathrm{Cl}_{6}$ than using other $\mathrm{C}_{x} \mathrm{Cl}_{y}$ compounds. This will be rationalized below.

Figure 4 shows high-resolution TEM (HRTEM) images of the materials prepared from $\mathrm{CaC}_{2}$ and $\mathrm{C}_{4} \mathrm{Cl}_{6}$. The interlayer spacing, which corresponds to the (002) distance of graphite carbon, decreases from 0.341 to $0.336 \mathrm{~nm}$ as the reaction temperature is increased from 1023 to $1223 \mathrm{~K}$. The data agree with the $d$ spacing values estimated from the selected area electron diffraction (SAED) patterns shown in the insets of Figure 4. The SAED pattern in Figure 4A shows a double-ringlike pattern, indicating a less ordered microcrystalline structure, while those in Figure 4B,C display dot patterns, suggesting more extended crystal ordering. The ordering of the graphite layer appears to be extensive. For example, an HRTEM image of a fibrous sample prepared from $\mathrm{C}_{4} \mathrm{Cl}_{6}$ at $1023 \mathrm{~K}$ showed that the material contained up to 100 layers of graphite sheets with the planes aligned to the fiber axis.

3.2. Preparation and Characterization of Silicon Crystals. From reactions between vaporized $\mathrm{SiCl}_{4}$ and $\mathrm{MSi}_{x}\left(\mathrm{Mg}_{2} \mathrm{Si}\right.$ and $\left.\mathrm{CaSi}_{2}\right)$ at $1023-1223 \mathrm{~K}$ and 1 atm, dark brown raw products were isolated. XRD studies of the raw products showed coexistence of $\mathrm{Si}$ (JCPDS 89-5012) and hydroyzed $\mathrm{MCl}_{2}$ salts $\left(\mathrm{MgCl}_{2}, \mathrm{JCPDS}\right.$ 89-1567; $\mathrm{MgCl}_{2}\left(\mathrm{H}_{2} \mathrm{O}\right)_{6}$, JCPDS 74-1039; $\mathrm{CaCl}_{2}\left(\mathrm{H}_{2} \mathrm{O}\right)_{2}$, JCPDS 70-0385; $\mathrm{CaCl}_{2}\left(\mathrm{H}_{2} \mathrm{O}\right)_{6}$, JCPDS 77-1782) in the solids. The chloride salts were removed by sublimation at $1073 \mathrm{~K}$ to offer pure $\mathrm{Si}$ products, as supported by the reflections from (111), (220), (311), (400), and (331) lattice planes shown in the XRD patterns. Thus, we conclude that the reactants were stoichiometricly converted into the products of silicon and metal chlorides. A summary of the reactions is listed in Table 2.

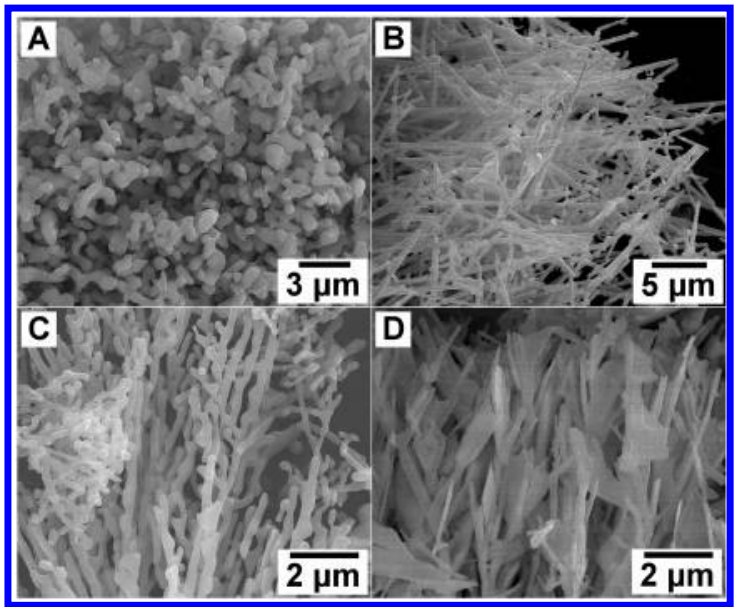

Figure 5. SEM images of silicon products prepared from $\mathrm{Mg}_{2} \mathrm{Si}$ and $\mathrm{SiCl}_{4}$ : (A) silicon particles, prepared at $1023 \mathrm{~K}$; (B) silicon wires, prepared at $1073 \mathrm{~K}$; (C) corallike silicon, prepared at $1123 \mathrm{~K}$; (D) flakelike silicon, prepared at $1223 \mathrm{~K}$.

Morphology Studies of Silicon Crystals by SEM. In Figure 5 , morphology of several different products prepared from $\mathrm{Mg}_{2^{-}}$ $\mathrm{Si}$ and $\mathrm{SiCl}_{4}$, after purification, is shown. We discover that the product morphology changes dramatically as the reaction temperature changes. The product formed at $1023 \mathrm{~K}$ is clustered particles, as shown in Figure 5A. When the reaction temperature is increased to $1073 \mathrm{~K}$, formation of wires is observed in Figure 5B. Figure 5C shows that corallike products are generated at $1123 \mathrm{~K}$. From the reaction temperature of $1223 \mathrm{~K}$, flakes attached to wire stems are formed and can be seen in Figure 5D. EDX data proved that all of the products, regardless of their difference in morphology, are composed of silicon only. No other signals were found in the sample. These are consistent with the XRD data. Morphology of the Si products prepared from $\mathrm{CaSi}_{2}$ and $\mathrm{SiCl}_{4}$ is similar to that of the ones synthesized by using $\mathrm{Mg}_{2} \mathrm{Si}$ and $\mathrm{SiCl}_{4}$. By simply varying the reaction temperature from 1023 to $1223 \mathrm{~K}$, the morphology changed from porous solids (formed at $1023 \mathrm{~K}$ ), to branched nanowires (formed at $1073 \mathrm{~K}$ ), to corallike structures (formed at $1123 \mathrm{~K}$ ), and finally to planar plates (formed at $1223 \mathrm{~K}$ ). EDX data also confirmed that the products are composed of silicon. Our observation suggests that the reaction temperature is the most important factor to affect the product morphology. This parallels greatly with the fabrication of graphite with different morphology discussed above. There, we also observed that the reaction temperature affected the product morphology in a comparable way. On the other hand, there is some dissimilarity. The most apparent one is that, in the cases of silicon growth, a unique corallike morphology was observed. The morphology suggests that the overall growth can be regarded as the development of various dendrite structures at different stages. By employing fractal analysis software Fractalyse, the projected two-dimensional fractal dimension $D$ is estimated for the silicon structures.

TABLE 2: Summary of Reaction Conditions and Product Morphology of Silicon Crystals Synthesized by Reacting $\mathrm{M}_{x} \mathrm{Si}_{y}$ and $\mathrm{SiCl}_{4}$ Vaporized at $255 \mathrm{~K} 1 \mathrm{~atm}$ under Ar Flowed at $5 \mathrm{~cm}^{3}(\mathrm{STP}) \mathrm{min}^{-1}$

\begin{tabular}{|c|c|c|}
\hline precursor $\mathrm{M}_{x} \mathrm{Si}_{y}$ & reacn temp $(\mathrm{K})$ & silicon product morphology \\
\hline \multirow{4}{*}{$\mathrm{CaSi}_{2}$} & 1023 & clustered particles: diam, one to few hundred nanometers; attached to neighboring ones \\
\hline & 1073 & wirelike: diam, $100-200 \mathrm{~nm}$; length, up to tens of micrometers \\
\hline & 1123 & corallike: trunk diam, one to few hundred nanometers; branches with similar diameters \\
\hline & 1223 & $\begin{array}{l}\text { flakelike: flakes branched from wirelike trunk; av flake length, up to several micrometers; } \\
\text { av flake width, } 200-800 \mathrm{~nm} \text {; trunk diam, several micrometers }\end{array}$ \\
\hline \multirow[t]{4}{*}{$\mathrm{Mg}_{2} \mathrm{Si}$} & 1023 & porous: irregular pores in irregularly shaped flakes; pore sizes, $200-800 \mathrm{~nm}$ \\
\hline & 1073 & wirelike: with protruded branches; diam, $50-100 \mathrm{~nm}$; length, up to few micrometers \\
\hline & 1123 & corallike: trunk diam, one to few hundred nanometers; branches with similar diameters \\
\hline & 1223 & planar: thickness, $100-200 \mathrm{~nm}$; diam, up to a micrometer \\
\hline
\end{tabular}




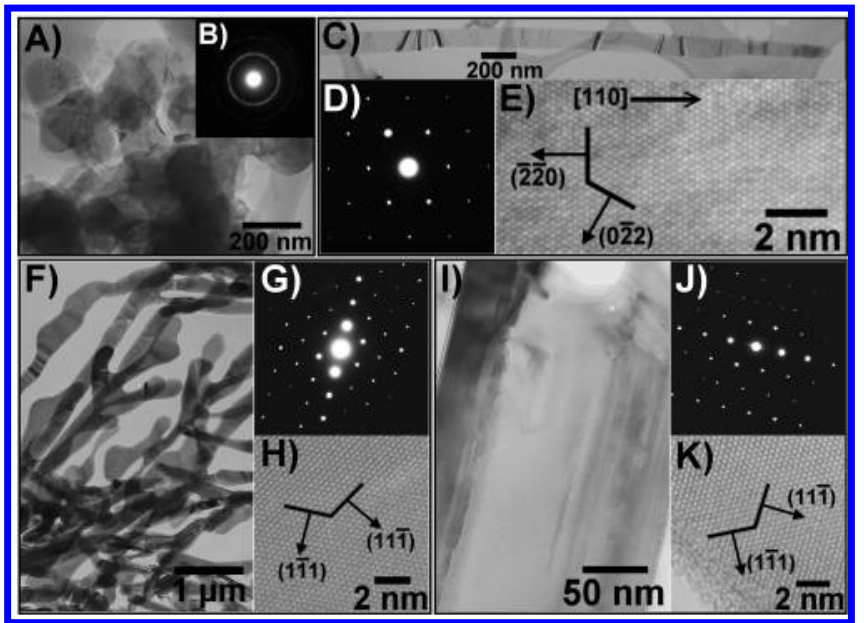

Figure 6. TEM studies of silicon products prepared from $\mathrm{Mg}_{2} \mathrm{Si}$ and $\mathrm{SiCl}_{4}$ : (A) low-magnification and (B) SAED images of clustered silicon particles prepared at $1023 \mathrm{~K}$; $(\mathrm{C}-\mathrm{E})$ images of a single silicon wire prepared at $1073 \mathrm{~K}$ [(C) low magnification, (D) SAED along [111] zone axis, and $(\mathrm{E})$ high resolution]; $(\mathrm{F}-\mathrm{H})$ images of corallike silicon prepared at $1123 \mathrm{~K}[(\mathrm{~F})$ low magnification, (G) SAED along [011] zone axis, and $(\mathrm{H})$ high resolution]; (I-K) images of flakelike silicon prepared at $1223 \mathrm{~K}$ [(I) low magnification, (J) SAED along [011] zone axis, and (K) high resolution].

For the samples prepared by reacting $\mathrm{Mg}_{2} \mathrm{Si}$ and $\mathrm{SiCl}_{4}, D$ increased as the reaction temperature was raised from 1023 to $1223 \mathrm{~K}$. Preliminary $D$ values of the samples in Figure 5A$5 \mathrm{D}$ were calculated to be $1.33,1.39,1.59$, and 1.88 , respectively. For the samples prepared by reacting $\mathrm{CaSi}_{2}$ and $\mathrm{SiCl}_{4}, D$ values were $1.49,1.68$, and 1.90 for the samples grown at 1073, 1123, and $1223 \mathrm{~K}$, respectively. Apparently, an analogous trend exists for the structural development of the carbon products.

The unique corallike morphology, observed in Figure 5C, may be attributed to a growth transition from wire to planar structures. Another possible reason is that the bonding preference of silicon allows it to branch easily. In solid state, silicon atoms favor $\mathrm{sp}^{3}$ hybridized bonding arrangements. We propose that when conditions are appropriate, the stacking of silicon atoms and clusters may protrude from the main growth axis and into the corallike morphology. On the other hand, graphite, with $\mathrm{sp}^{2}$ hybridized carbon connections favoring planar sheets of hexagonal networks, is more difficult to extend out unless less stabilized five- or seven-membered rings are formed. ${ }^{41}$ Another interesting observation is that, in the graphite growth, porous structures were formed at 973-1023 K. A parallel case, silicon with a porous structure, was grown at $1023 \mathrm{~K}$ employing $\mathrm{CaSi}_{2}$. In contrast, clustered silicon particles were synthesized at the same temperature using $\mathrm{Mg}_{2} \mathrm{Si}$ (Figure 5A). These observations suggest that the networked solids and metal chloride salts probably act alternatively as mold and cast after phase segregation at different conditions. This will be discussed more as follows.

Structural Characterization of Silicon Crystals by TEM and Raman. The silicon materials were further stucturally analyzed by using TEM. Figure 6 shows the images of the samples prepared from the reactions of $\mathrm{SiCl}_{4}$ and $\mathrm{Mg}_{2} \mathrm{Si}$. Figure 6A displays that the particles prepared at $1023 \mathrm{~K}$, with average diameters of $150-300 \mathrm{~nm}$, are clustered together. The selected area electron (SAED) in Figure 6B shows a pattern consiting of (111), (200), and (311) rings of a cubic phase material. From the pattern, the lattice parameter $a$ is calculated to be 0.547 $\mathrm{nm}$, which is close to the value of bulk $\mathrm{Si}, 0.543 \mathrm{~nm}$. Figure 6C shows a low-resolution image of a single flakelike silicon wire grown at $1073 \mathrm{~K}$. The diameter of the wire ranges from
100 to $200 \mathrm{~nm}$. The dot pattern in the ED study in Figure 6D suggets that the wire can be indexed to the [111] zone axis of single-crystal silicon. From the image, the lattice parameter $a$ is estimated to be $0.549 \mathrm{~nm}$. Figure 6E shows a high-resolution lattice image of the wire. The spacing between the parallel fringes from the crystalline structure was measured to be 0.192 $\mathrm{nm}$. This is equal to the spacing of the $\{110\}$ planes of silicon. The image also suggets that the defect-free single-crystal wire grows along the [110] direction. A low-magnification TEM image in Figure $6 \mathrm{~F}$ shows that the product grown at $1123 \mathrm{~K}$ is corallike. The dot pattern in Figure 6G suggests that the sample, viewed along the [011] zone axis of $\mathrm{Si}$, is single crystalline. A high-resolution image in Figure $6 \mathrm{H}$ suggests that the lattice fringes are spaced $0.31 \mathrm{~nm}$ apart. This distance coincides well with the $\{111\}$ interplane distance of silicon. A TEM image shown in Figure 6I reveals a representative flakelike material isolated from the sample prepared at $1223 \mathrm{~K}$. The sample also presents a dot pattern in the ED study in Figure $6 \mathrm{~J}$. This can be indexed to the [011] zone axis of cubic phase silicon. A highresolution image in Figure 6K reveals that the crystalline sample has an interlayer distance of $0.31 \mathrm{~nm}$, which is identical to the $\{111\}$ lattice plane distance of silicon. In addition, a thin $(<1$ $\mathrm{nm}$ ) amorphous surface layer is revealed. It is speculated to be a layer of silica, formed by the hydrolysis of residual $\mathrm{Cl}$ atoms on the $\mathrm{Si}$ surface. We assume that the silica layer exists in all the $\mathrm{Si}$ samples prepared in this study.

Raman scattering is very sensitive to lattice microstructures. Frequently, it is a useful tool to determine crystal symmetry of micro- and nanocrystalline materials. Here, Raman scattering was carried out to verify different silicon morphologies found in this study. Most of the samples exhibited a prominent peak near $520 \mathrm{~cm}^{-1}$, corresponding to the scattering of the first-order optical phonon of crystalline silicon. ${ }^{42}$ For example, the clustered particles showed a symmetrical peak at $519.8 \mathrm{~cm}^{-1}$. As the size decreased and the morphology became more asymmetrical, the peak downshifted and broadened asymmetrically. The corallike structures showed most significant shifts. This reflects the nature that they were less symmetric and probably with more defects due to the more dendridic growth. Since nearly all structures had sizes greater than $20 \mathrm{~nm}$, the downshift of the peaks at 520 $\mathrm{nm}$ was not caused by the size confinement effect. There were no signals observed for amorphous silicon $\left(480 \mathrm{~cm}^{-1}\right)$, silicon dioxide (476 and $\left.460 \mathrm{~cm}^{-1}\right)$, and partially oxidized silicon $\left(\mathrm{SiO}_{x}\right)$ shell (between 400 and $550 \mathrm{~cm}^{-1}$ ), suggesting that the samples were highly purified crystalline silicon. ${ }^{42-46}$

\section{Discussion}

4.1. Phase Segregation. An illustrated reaction pathway for fabricating porous, fibrous and lamellar carbon materials from $\mathrm{CaC}_{2}$ and $\mathrm{C}_{x} \mathrm{Cl}_{y}$ is shown in Scheme 1. At different temperatures, the products $\mathrm{CaCl}_{2}$ and $\mathrm{C}$, with large difference in surface energies, undergo phase segregation and templating of each other cooperatively into the observed morphology. Since the reactions between $\mathrm{SiCl}_{4}$ and $\mathrm{M}_{x} \mathrm{Si}_{y}$ also showed parallel results, a similar reaction scheme can be applied. These processes appear to be closely related to spinodal decomposition described in literature. ${ }^{27}$ In addition, the phenomena observed in this study show parallels to what is observed in copolymer systems. In polymer science, many researchers have examined morphology alteration caused by phase segregation in block copolymer systems. ${ }^{28,29}$ They have discovered that the following parameters affect the structure and morphology of block copolymers greatly: $\chi N(\chi$ is the Flory parameter characterizing interactions between components $\mathrm{A}$ and $\mathrm{B}$ in the copolymers; $N$ is the polymer index), 
SCHEME 1: Summary of Textured Graphite Formation from the Reaction between $\mathrm{CaC}_{2}$ and $\mathrm{C}_{x} \mathrm{Cl}_{y}$

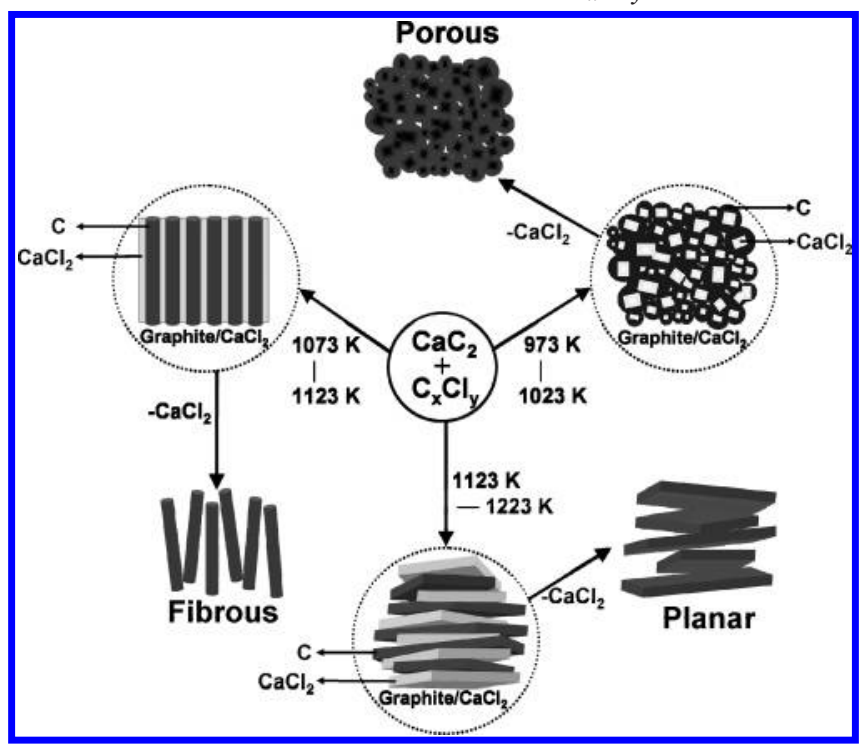

which is dependent on temperature, and $f$ ( $f$ is the fraction of monomers $\mathrm{A}$ in a chain). In many ways, the phenomenon observed in copolymer systems parallels what is observed in this study. In this study, we discovered that the overall product morphology is less affected by the reactants nature but more strongly by reaction temperature. This is analogous to the dependence of block copolymer morphology on the parameters $\chi N$.

Interestingly in this study, comparable product morphology variations are observed in both graphite and silicon cases despite the reactant and product differences. There must be some common influential factors controlling the final outcomes. It is reasonable to assume that both graphite and silicon network solids and $\mathrm{MCl}_{2}$ salt products are formed initially as homogeneous mixtures in the reactions in the VSRG investigated here. However, due to a large difference of interactions between the salts and the network solids, they do not dissolve each other well according to "the like-dissolves-like rule" and undergo spinodal decomposition. The ionic salt products $\mathrm{MgCl}_{2}$ and $\mathrm{CaCl}_{2}$ are relatively low melting, 985 and $1045 \mathrm{~K}$, respectively. They probably are in a free-flowing liquid state in the reaction processes. Both silicon and graphite network solids are high melting, 2683 and $3948 \mathrm{~K}$, respectively. The as-formed molecular level Si and C fragments and clusters, generated at the vapor-solid reaction interface, probably phase-separated from the ionic media and solidify rapidly into the growing crystal lattice via an Ostwald ripening type process. ${ }^{27,47}$ The coexistence of solid and liquid phases is typical in an eutectic system. ${ }^{27}$ During the process, the products perform the roles of mold and cast, which influence the final product shape cooperatively. To minimize the free energy, the growing nanocrystals would develop into a more stable morphology. Thus, with increasing reaction temperature, the crystal structural dimension increases from zero (porous or particle) to one (fibrous or wire), and finally to two (planar or plate). In addition, the fractal dimension increases as well. The final product morphology resembles many observed for eutectic alloys. ${ }^{27}$ For other systems reported in literature, evolution of a fractal dimension has been found to be dependent on factors other than temperature. ${ }^{48-50}$

4.2. Composition Effect. Products prepared from $\mathrm{CaC}_{2}$ and halogen molecules $\mathrm{Br}_{2}$ and $\mathrm{I}_{2}$ at $1023 \mathrm{~K}$ were particles. This morphology appears to be a reverse of the porous structure found for the samples generated by employing $\mathrm{CaC}_{2}$ and $\mathrm{C}_{x} \mathrm{Cl}_{y}$ at

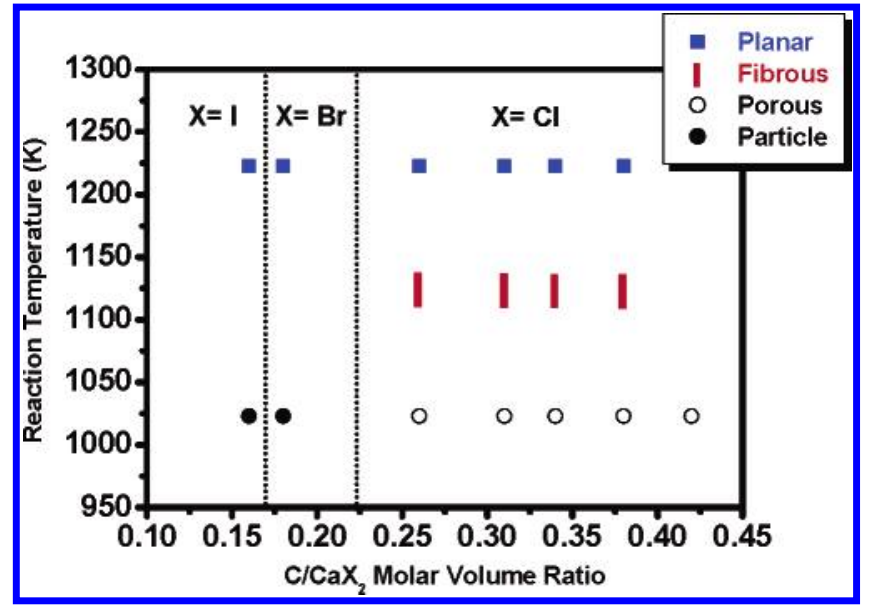

Figure 7. Summary of graphite morphology affected by the reaction temperature and $\mathrm{C} / \mathrm{CaX}_{2}$ molar volume ratio.

$1023 \mathrm{~K}$. We attribute the reason for this to the molar volume ratio of the products graphite and $\mathrm{CaX}_{2}$. We suggest that the higher content product serves as the main skeleton while the lower content one occupies the remaining space as distributed particles. According to the reaction stoichiometry, the $\mathrm{C} / \mathrm{CaX}_{2}$ molar volume ratios from the reactions between $\mathrm{CaC}_{2}$ and $\mathrm{X}_{2}$ are 0.18 and 0.16 , for $\mathrm{X}=\mathrm{Br}$ and $\mathrm{I}$, respectively. On the other hand, the $\mathrm{C} / \mathrm{CaCl}_{2}$ molar volume ratios from the reaction between $\mathrm{CaC}_{2}$ and $\mathrm{C}_{x} \mathrm{Cl}_{y}\left(\mathrm{CCl}_{4}, \mathrm{C}_{2} \mathrm{Cl}_{4}, \mathrm{C}_{4} \mathrm{Cl}_{6}, \mathrm{C}_{5} \mathrm{Cl}_{6}\right.$, and $\mathrm{C}_{6-}$ $\mathrm{Cl}_{6}$ ) are from 0.26 to 0.42 . At the reaction temperature of 1023 $\mathrm{K}$, a clear distinction of morphology for the two cases, particle and porous, is observed. Therefore, in the first example, $\mathrm{CaBr}_{2}$ and $\mathrm{CaI}_{2}$ form the major structure, while $\mathrm{C}$ grows into separate particles inside it. In the second case, the high $\mathrm{C}$ content creates the main $\mathrm{C}$ body encapsulating the minor $\mathrm{CaCl}_{2}$ crystals. After removal of the salts, the corresponding particle and porous structures are observed. At high reaction temperatures, the phasesegregated products develop in the same dimensions and do not create distinctively different morphology. A summary of effects of reaction temperature and molar volume ratio on the products is shown in Figure 7.

As mentioned above, a similar particle/porous variation was observed in the silicon case. The role of mold and cast showed a clear reverse for the samples prepared at $1023 \mathrm{~K}$. The Si sample prepared from $\mathrm{Mg}_{2} \mathrm{Si}$ showed a clustered-particle morphology (Figure 5A), while the product formed from $\mathrm{CaSi}_{2}$ displayed a porous morphology. We attribute the phenomenon to the $\mathrm{Si} / \mathrm{salt}$ molar volume ratio of the products. From the reaction stoichiometry, the $\mathrm{Si} / \mathrm{MgCl}_{2}$ molar volume ratio is 0.29 , while the $\mathrm{Si} / \mathrm{CaCl}_{2}$ molar volume ratio is 0.58 . The observation again suggests that the higher content component in the phasesegregated products forms the major framework, while the lower content one embeds within it. Thus, in the $\mathrm{Si} / \mathrm{MgCl}_{2}$ case, the high-content $\mathrm{MgCl}_{2}$ formed the main structure, while the minor Si crystallized into separate particles inside the solid salt. In the second case, the higher content silicon formed the host encapsulating the lower content $\mathrm{CaCl}_{2}$ crystals. After removal of the salts, the observed $\mathrm{Si}$ structures are shown. At higher reaction temperatures, the morphology difference of Si prepared from $\mathrm{Mg}_{2} \mathrm{Si}$ and $\mathrm{CaSi}_{2}$ diminishes. The effects of reaction temperature and molar volume ratio on the $\mathrm{Si}$ products are summarized in Figure 8.

4.3. Low-Temperature Graphitization. In common practice, it frequently requires high-temperature $(>2273 \mathrm{~K})$ graphitization processes to align atoms in disordered carbon materials. ${ }^{51}$ Interesting in this study, comparatively ordered graphite materi- 


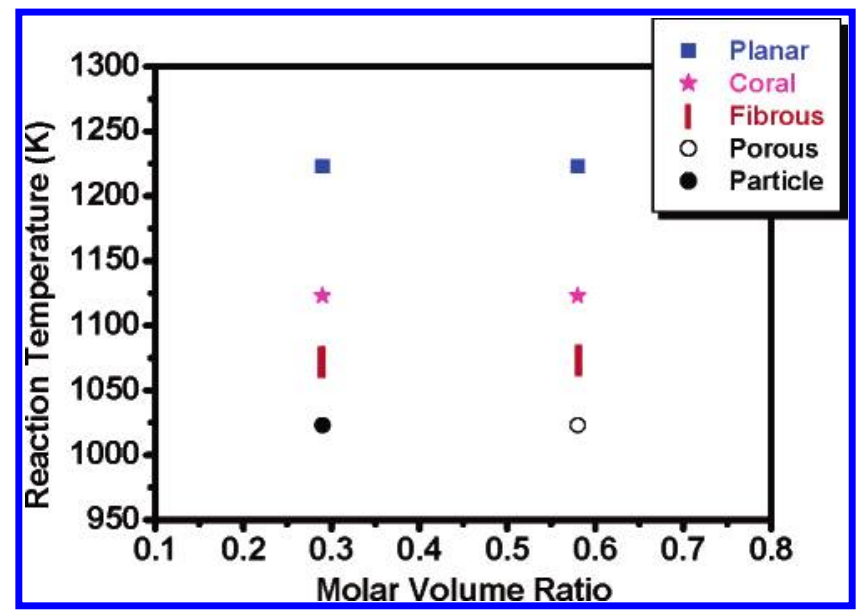

Figure 8. Summary of silicon morphology affected by the reaction temperature and $\mathrm{Si} / \mathrm{MCl}_{2}(\mathrm{M}=\mathrm{Mg}, \mathrm{Ca})$ molar volume ratio.

als can be grown at temperatures as low as $1023 \mathrm{~K}$. This is probably due to the exothermic nature of these reactions, which provide energetically favored local reaction sites. For example, the estimated standard enthalpy of reaction $\Delta H_{\mathrm{r}}{ }^{\mathrm{O}}=-689 \mathrm{~kJ} /$ mol of $\mathrm{CaC}_{2}$ consumed in the reaction between $\mathrm{CaC}_{2}$ and $\mathrm{CCl}_{4}{ }^{52}$ Variation in the estimated enthalpy values generated by stoichiometry and reaction temperature differences is insignificant because the heat capacity differences do not affect these thermodynamic data much. ${ }^{52}$ The graphite products formed from $\mathrm{C}_{4} \mathrm{Cl}_{6}$ were more ordered. As shown in Figure 3, higher La and $\mathrm{Lc}$ values are formed at comparable temperatures using $\mathrm{C}_{4} \mathrm{Cl}_{6}$. Apparently, the more exothermic $\Delta H_{\mathrm{r}}{ }^{\circ},-728 \mathrm{~kJ} / \mathrm{mol}$ of $\mathrm{CaC}_{2}$ used, appears to be the cause for the formation of more ordered products in the case involving $\mathrm{C}_{4} \mathrm{Cl}_{6}{ }^{52} \mathrm{On}$ the other hand, for the reaction employing $\mathrm{C}_{2} \mathrm{Cl}_{4}$, an indistinguishable $\Delta H_{\mathrm{r}}{ }^{\mathrm{O}}=-730$ $\mathrm{kJ} / \mathrm{mol}$ of $\mathrm{CaC}_{2}$ used is found. ${ }^{52}$ The carbon products prepared from $\mathrm{C}_{2} \mathrm{Cl}_{4}$ did not show the same degree of orderness as the ones formed from $\mathrm{C}_{4} \mathrm{Cl}_{6}$. Thus, the aspect of thermodynamics cannot explain why using $\mathrm{C}_{4} \mathrm{Cl}_{6}$ produced graphite as ordered as one case heated at $2473 \mathrm{~K}$. A better rationalization is that the reaction between $\mathrm{CaC}_{2}$ and $\mathrm{C}_{4} \mathrm{Cl}_{6}$ may proceed via an energetically favored inverse Diels-Alder reaction route. ${ }^{53} \mathrm{In}$ the $\mathrm{CaC}_{2}$ lattice, electron-rich $\pi$ bonds of $\mathrm{C}_{2}{ }^{2-}$ units may act as dienophiles, while $\mathrm{C}_{4} \mathrm{Cl}_{6}$ molecules, due to the presence of electron-withdrawing $\mathrm{Cl}$ atoms, may be viewed as electron-poor dienes. In an inverse Diels-Alder reaction, the HOMOdienophile to LUMO-diene interaction would provide a lowenergy pathway for the $\mathrm{C}_{2}$ and $\mathrm{C}_{4}$ units to overcome the barrier and to generate a six-membered $\mathrm{C}_{6}$ ring, which is the basic building block of graphite. ${ }^{54,55}$ On the basis of the kinetic reason, we may rationalize why more graphitized carbon materials are grown in the reactions employing $\mathrm{C}_{4} \mathrm{Cl}_{6}$ than in the other ones.

4.4. Effect of $\mathrm{CaX}_{2}(\mathbf{X}=\mathbf{F}, \mathbf{C l})$ Salts. Previously, in an analogous reaction between $\mathrm{CaC}_{2}$ and $\mathrm{C}_{6} \mathrm{~F}_{6}$ at $973 \mathrm{~K}$, phasesegregated $\mathrm{CaF}_{2} / a-\mathrm{C}$ core-shell nanowires were grown. ${ }^{23}$ These nanowires showed morphology and crystallinity significantly different from the products synthesized in this study. There are several possible reasons to explain the distinction. The first one is that the melting point of $\mathrm{CaCl}_{2}, 1045 \mathrm{~K}$, is considerably lower than that of $\mathrm{CaF}_{2}, 1676 \mathrm{~K}$. The flexible molten $\mathrm{CaCl}_{2}$ formed in this study would sculpt the other product graphite into a wide range of morphology easily. The other possible reason may originate from the difference between $\mathrm{C}-\mathrm{Cl}$ and $\mathrm{C}-\mathrm{F}$ bond strengths, 339 and $443 \mathrm{~kJ} / \mathrm{mol}$, respectively. ${ }^{56}$ The strong $\mathrm{C}-\mathrm{F}$ linkage in $\mathrm{C}_{6} \mathrm{~F}_{6}$ may not dissociate completely in the reaction, and the residual $\mathrm{C}-\mathrm{F}$ bonds may disarray the graphite layers. They may also bind well at the interface between carbon and
$\mathrm{CaF}_{2}$ phases. In contrast, the $\mathrm{C}-\mathrm{Cl}$ bonds should break more readily. The interfacial binding between graphite and $\mathrm{CaCl}_{2}$ is weak due to a large difference in surface energies. Thus, the molten $\mathrm{CaCl}_{2}$ can act as a flexible mold more readily. This parallels the phase segregation and morphology alteration commonly observed in eutectic alloys and diblock and triblock copolymer systems. ${ }^{27-29}$

\section{Conclusions}

In summary, we have demonstrated the first time that alternation of graphite and silicon morphologies can be achieved easily via simple VSRG reactions employing $\mathrm{CaC}_{2}$ to react with organoperchloro compounds and employing $\mathrm{M}_{x} \mathrm{Si}_{y}\left(\mathrm{Mg}_{2} \mathrm{Si}\right.$ and $\mathrm{CaSi}_{2}$ ) to react with $\mathrm{SiCl}_{4}$, respectively, at favorable reaction temperatures. The reactions proceed without assistance from added templates and catalysts, application of a special source of energies, and utilization of special pressure reactors. Via spinodal decomposition, the network solid and the salt products phase-segregate into self-templating mold and cast. Morphology of the products generated by the self-templating process depends on the reaction temperature and the product stoichiometry. The graphite and the silicon prepared from the simple VSRG show wide variations in dimension scales and morphology, including particle, porous, fibrous/wirelike, corallike, and plate/planar structures. The phenomena found in these inorganic systems also show high resemblance to the morphology alteration frequently found in eutectic alloys and diblock-triblock copolymer systems. ${ }^{27-29}$ The graphites grown in the study are highly ordered for the temperature employed. We attribute this to the exothermic nature of the reactions. We expect these uniquely shaped materials may find many special applications in the future.

Acknowledgment. This work was supported by the National Science Council and the Ministry of Education of Taiwan, Republic of China.

Supporting Information Available: SEM, TEM, HRTEM images, XRD patterns, and Raman spectra of the graphite and silicon products formed in this study. These materials are available free of charge via the Internet at http://pubs.acs.org.

\section{References and Notes}

(1) Milliron, D. J.; Hughes, S. M.; Cui, Y.; Manna, L.; Li, J.; Wang, L.-W.; Alivisatos, A. P. Nature 2004, 430, 190-195.

(2) Peng, X.; Manna, L.; Yang, W.; Wickham, J.; Scher, E.; Kadavanich, A.; Alivisatos, A. P. Nature 2000, 404, 59-61.

(3) Pileni, M. Nat. Mater. 2003, 2, 145-150.

(4) Kim, F.; Connor, S.; Sond, H.; Kuykendall, T.; Yang, P. Angew. Chem. 2004, 43, 3673-3677.

(5) Chen, J.; Herricks, T.; Xia, Y. Angew. Chem. 2005, 44, 25892592.

(6) Yu, T.; Joo, J.; Park, Y. I.; Hyeon, T. Angew. Chem. 2005, 44, $7411-7414$ 8649.

(7) Tapan, T. K.; Murphy, C. J. J. Am. Chem. Soc. 2004, 126, 8648-

(8) Burda, C.; Chen, X.; Narayanan, R.; El-Sayed, M. A. Chem. Rev 2005, 105, 1025-1102.

(9) Liang, C.; Hong, K.; Guiochon, G. A.; Mays, J. W.; Dai, S. Angew. Chem. 2004, 43, 5785-5789.

(10) Yu, J.-S.; Kang, S.; Yoon, S. B.; Chai, G. J. Am. Chem. Soc. 2002 124, 9382-9383.

(11) Ryoo, R.; Joo, S. H.; Kruk, M.; Jaroniec, M. Adv. Mater. 2001 $13,677-681$

(12) Lim, S.; Yoon, S.-H.; Shimizu, Y.; Jung, H.; Mochida, I. Langmuir 2004, 20, 5559-5563.

(13) Tang, C.; Tracz, A.; Kruk, M.; Zang, R.; Smilgies, D.-M.; Matyjaszewski, K.; Kowalewski, T. J. Am. Chem. Soc. 2005, 127, 69186919. 
(14) Gudihsen, M. S.; Wang, J.; Lieber, C. M. J. Am. Chem. Soc. 2000, $122,8801-8802$.

(15) Westwater, J.; Gosain, D. P.; Tomiya, S,; Usui, S.; Ruda, H. J. Vac. Sci. Technol., B 1997, 15, 554-557.

(16) Hu, J.; Odom, T. W.; Lieber, C. M. Acc. Chem. Res. 1999, 32, $435-445$.

(17) Morales, A. M.; Lieber, C. M. Science 1998, 279, 208-211.

(18) Holmes, J. D.; Johnston, K. P.; Doty, R. C.; Korgel, B. A. Science 2000, 287, 1471-1473.

(19) Shi, W.; Peng, H.; Wang, N.; Li, C. P.; Xu, L.; Lee, C. S.; Kalish,

R.; Lee, S. T. J. Am. Chem. Soc. 2001, 123, 11095-11096.

(20) Canham, L. T. Appl. Phy. Lett. 1990, 57, 1046-1048.

(21) Yen, M.-Y.; Chiu, C.-W.; Hsia, C.-H.; Chen, F.-R.; Kai, J.-J.; Lee,

C.-Y.; Chiu, H.-T. Adv. Mater. 2003, 15, 235-237.

(22) Hsia, C.-H.; Yen, M.-Y.; Lin, C.-C.; Chiu, H.-T.; Lee, C.-Y. J. Am. Chem. Soc. 2003, 125, 9940-9941.

(23) Huang, C.-H.; Chang, Y.-H.; Lee, C.-Y.; Chiu, H.-T. Langmuir 2006, 22, 10-12.

(24) Wang, C.-H.; Chang, Y.-H.; Yen, M.-Y.; Peng, C.-W.; Lee, C.Y.; Chiu, H.-T. Adv. Mater. 2005, 17, 419-422.

(25) Brian, J.; Charles, F. K. J. Sediment. Petrol. 1993, 63, 1018-1031.

(26) Guillaume, C.; Olivier, B.; Christophe, D.; Michel, A.; Eric, P. V. Catena 2005, 59, 1-17.

(27) Jackson, K. A. Kinetic Processes: Crystal Growth, Diffusion, and Phase Transitions in Materials: Wiley-VCH: Weinheim, Germany, 2004; Chapters 23-28.

(28) Leibler, L. Macromolecules 1980, 13, 1602-1617.

(29) Matsen, M. W.; Bates, F. S. Macromolecules 1996, 29, $7641-$ 7644.

(30) Bates, F. S.; Fredrickson, G. H. Annu. Rev. Phys. Chem. 1990, 41, $525-557$

(31) Bockstaller, M. R.; Mickiewicz, R. A.; Thomas, E. L. Adv. Mater. 2005, 17, 1331-1349. 286.

(32) Warren, B. E.; Bodenstein, P. Acta Crvstallogr. 1965, 18, 282-

(33) Vix-Guterl, C.; Couzi, M.; Dentzer, J.; Trinquecoste, M.; Delhaes, P. J. Phys. Chem. B 2004, 108, 19361-19367.

(34) Yoon, S. B.; Chai, G. S.; Kang, S. K.; Yu, J. S.; Gierszal, K. P.; Jaroniec. M. J. Am. Chem. Soc. 2005, 127, 4188-4189.

(35) Zeng, Z.; Natesan, K. Chem. Mater. 2003, 15, 872-878.

(36) Dresselhaus, M. S.; Dresselhaus, G.; Pimenta, M. A.; Eklund, P. C. In Analytical Applications of Raman Spectroscopy; Pelletier, M. J., Ed.; Blackwell Science: Oxford, U.K., 1999; Chapter 9.
(37) Chieu, T. C.; Dresselhaus, M. S. Endo, M. Phys. Rev. B 1982, 26 , 5867-5877.

(38) Hou, H.; Schaper, A. K.; Jun, Z.; Weller, F.; Greiner, A. Chem. Mater. 2003, 15, 580-585.

(39) Liu, J.; Shao, M.; Chen, X.; Yu, W.; Liu, X.; Qian, Y. J. Am. Chem. Soc. 2003, 125, 8088-8089.

(40) Liang, C.; Dai, S.; Guiochon, G. Anal. Chem. 2003, 75, 49044912 .

(41) Biro, L. P.; Bernardo, C. A.; Tibbetts, G. G.; Lambin, Ph. In Carbon Filaments and Nanotubes: Common Origins, Differing Applications; NATO Science Series; Kluwer: Dordrecht, The Netherlands, 2001; pp 151-153.

(42) Dapeng, B. L.; Zhang, S. L. Phys. Rev. B 1999, 59, 1645-1648.

(43) Zhang, Y. F.; Tang, Y. H.; Wang, N.; Yu, D. P.; Lee, C. S.; Bello,

I.; Lee, S. T. Appl. Phys. Lett. 1998, 72, 1835-1837.

(44) Wang, N.; Tang, Y. H.; Zhang, Y. F.; Lee, C. S.; Bello, I.; Lee, S. T. Chem. Phys. Lett. 1999, 299, 237-242.

(45) Chi, W. S.; Peng, H. Y.; Zheng, Y. F.; Wang, N.; Shang, N. G.; Pan, Z. W.; Lee, C. S.; Lee, S. T. Adv. Mater. 2000, 12, 1343-1345.

(46) Li, W. N.; Ding, Y. S.; Yuan, J.; Gomez, S.; Suib, S. L.; Galasso, F. S.; DiCarlo, J. F. J. Phys. Chem. B 2005, 109, 3291-3297.

(47) Voorhees, P. W. J. Stat. Phys. 1985, 38, 231-252.

(48) Guzmán-Vargas, A.; Lima, E.; Delahay, G.; Coq, B.; Lara, V. Ind. Eng. Chem. Res. 2006, 45, 4163-4168.

(49) Phonthammachai, N.; Chairassameewong, T.; Gulari, E.; Jamieson, A. M.; Wongkasemjit, S. Microporous Mesoporous Mater. 2003, 66, 261271

(50) Lima, E.; Valente, J.; Bosch, P.; Lara, V. J. Phys. Chem. B 2005, $109,17435-17439$

(51) Colligan, G.; Galasso, F. Nature 1961, 190, 621-621.

(52) NIST Chemistry WebBook; NIST Standard Reference Database No. 69; National Institute of Standards and Technology: Gaithersburg, MD, 2005; http://webbook.nist.gov/chemistry. Reaction-Web, Facility for the Analysis of Chemical Thermodynamics; CRCT, École Polytechnique de Montréal: Montréal, http://www.crct.polymtl.ca/fact/.

(53) Spino, C.; Pesant, M.; Dory, Y. Angew. Chem. 1998, 37, 32623265 .

(54) Dewar, M. J. S.; Pierini, A. B. J. Am. Chem. Soc. 1984, 106, 203208.

(55) Peter, K.; Vollhardt, C.; Schore, N. E. Organic Chemistry, 3rd ed.; Freeman Press: New York, 1998; pp 600-604.

(56) Kerr, J. A. Chem. Rev. 1966, 66, 465-500 